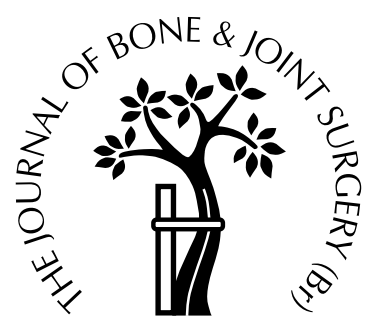

\title{
Choline acetyltransferase activity and evoked spinal cord potentials for diagnosis of brachial plexus injury
}

\author{
Y. Hattori, K. Doi, V. Dhawan, K. Ikeda, K. Kaneko, R. Ohi \\ From the Ogori Daiichi General Hospital and Yamaguchi University School of Medicine, \\ Yamaguchi, Japan
}

\begin{abstract}
7 he purpose of this study is to investigate the diagnostic value of evoked spinal cord potentials (ESCPs) and choline acetyltransferase (CAT) activity during exploration of injuries to the brachial plexus. We assessed 25 spinal roots in 19 patients. The results of the two investigations were consistent in all except two roots. Although assessment of ESCPs is easy and quick, it mainly records the nerve potentials along the sensory pathway. Although measurement of CAT activity needs a specimen of the nerve and the availability of a radioisotope laboratory, it gives direct information regarding the motor function of ventral spinal roots. These two techniques should be complementary to each other in order to achieve a more accurate diagnosis.
\end{abstract}

J Bone Joint Surg [Br] 2004;86-B:70-3.

Received 3 September 2002; Accepted after revision 28 July 2003

At present, the most reliable method for diagnosis of injuries to the brachial plexus is by surgical exploration together with intra-operative electrophysiological tests, such as somatosensory evoked potentials (SEPs) ${ }^{1,2}$ or evoked spinal cord potentials (ESCPs). ${ }^{3,4}$ We have already described the usefulness of the latter. ${ }^{4}$ Although the main purpose of surgery to the brachial plexus is to restore motor function, these tests mainly record the nerve potentials belonging to the afferent sensory pathway. ${ }^{5}$ It has been assumed that the ventral and dorsal roots are usually damaged together. However, the ventral roots may be more susceptible to traction

Y. Hattori, MD, Orthopaedic Surgeon

K. Doi, MD, Orthopaedic Surgeon

V. Dhawan, MD, Orthopaedic Surgeon

K. Ikeda, MD, Orthopaedic Surgeon

Ogori Daiichi General Hospital, Shimogo, 862-3 Ogori, Yamaguchi 7540002, Japan.

K. Kaneko, MD, Orthopaedic Surgeon

R. Ohi, MD, Orthopaedic Surgeon

Yamaguchi University School of Medicine, Ube, Yamaguchi, Japan.

Correspondence should be sent to Dr Y. Hattori.

(C)2004 British Editorial Society of Bone and Joint Surgery doi:10.1302/0301-620X.86B1.13844 \$2.00 injury than the dorsal roots with consequent dissociation in the functional deficit between motor and sensory function in some patients. ${ }^{6}$ Hence, although the ESCPs are considered to be one of the most reliable methods to distinguish between pre- and post-ganglionic injuries, there is a potential risk of false positive or false negative results.

Since 1996, we have used the measurement of choline acetyltransferase (CAT) activity in injured spinal roots, in addition, to achieve a more accurate diagnosis. ${ }^{7}$ We now describe our findings in a larger series.

\section{Patients and Methods}

Patients. Nineteen patients with traumatic lesions of the brachial plexus who underwent surgical exploration between March 1996 and April 2001 were included in this study (Table I). The mean age was 26.3 years (5 to 69) at the time of operation. Fifteen patients had clinical evidence of a complete brachial plexus lesion, three had involvement of $\mathrm{C} 5$ and $\mathrm{C} 6$ and one of $\mathrm{C} 5$ and $\mathrm{C} 7$. The time interval between injury and exploration ranged from one to ten months (mean 3.8). The total number of nerve roots included in this study was 25 . Roots in the lower plexus which had clinical evidence of pre-ganglionic injury and those demonstrating a pseudomeningocele on myelography were not examined. There were 18 C5 roots and seven C6 roots. Surgical exploration was carried out in the usual manner and injured spinal roots were prepared for the measurement of ESCPs and CAT activity. After the scarred ends of the injured roots were shortened, examination through the surgical microscope revealed cross sections, predominantly containing nerve tissue and not fibrotic tissue, which made them suitable for this study.

The measurement of ESCPs. Following stimulation of the root stump, these potentials were recorded from a catheter electrode placed in the posterior cervical epidural space according to the modified technique of Murase et al. ${ }^{3}$ The potentials were recorded by an electromyograph (SYNAX 1100; NEC San-ei Co Ltd, Tokyo, Japan), and averaged 300 to 500 responses from seven stimulations per second. The peak to peak amplitude was measured.

Measurement of the CAT activity. This was carried out using the modified method of Engel et al ${ }^{8}$ and Hattori et al. ${ }^{9}$ The formation of acetylcholine labelled with ${ }^{14} \mathrm{C}$ from 
Table I. Overall results of the study

\begin{tabular}{|c|c|c|c|c|c|c|c|c|c|c|c|c|c|}
\hline Case & Age & Gender & $\begin{array}{l}\text { Time of } \\
\text { injury to } \\
\text { op } \\
\text { (month) }\end{array}$ & $\begin{array}{l}\text { Type of } \\
\text { injury }\end{array}$ & Root & Diagnosis* & $\begin{array}{l}\text { Amplitude } \\
\text { of } \\
\text { ESCPs }\end{array}$ & $\begin{array}{l}\text { CAT } \\
\text { of each } \\
\text { fascicle }\end{array}$ & $\begin{array}{l}\text { Total } \\
\text { amount } \\
\text { of CAT }\end{array}$ & $\begin{array}{l}\text { Target } \\
\text { of } \\
\text { nerve } \\
\text { graft } \dagger\end{array}$ & $\begin{array}{l}\text { Re- } \\
\text { innervation } \\
\text { of target } \\
\text { muscle } \\
\text { (months) }\end{array}$ & $\begin{array}{l}\text { Shoulder } \\
\text { abduction } \\
\left(^{\circ}\right)\end{array}$ & $\begin{array}{l}\text { Follow-up } \\
\text { (months) }\end{array}$ \\
\hline \multirow[t]{2}{*}{1} & 19 & M & 7 & Total & $\mathrm{C} 5$ & un-R & 0 & 242,174 & 416 & $(-)$ & & & \\
\hline & & & & & C6 & un-R & 0 & 161,191 & 352 & $(-)$ & & & \\
\hline \multirow[t]{2}{*}{2} & 21 & M & 1.5 & Total & $\mathrm{C} 5$ & un- $R$ & 0 & 402,415 & 817 & $(-)$ & & & \\
\hline & & & & & C6 & un-R & 1.43 & 348,243 & 591 & $(-)$ & & & \\
\hline 3 & 34 & M & 3 & Total & $\mathrm{C} 5$ & un- $R$ & 0 & 326,485 & 811 & $(-)$ & & & \\
\hline 4 & 19 & M & 2 & $\mathrm{C} 5,6$ & $\mathrm{C} 5$ & un-R & 0 & $309,237,305$ & 851 & $(-)$ & & & \\
\hline 5 & 21 & M & 2 & Total & C6 & un- $R$ & 0 & 346,452 & 798 & $(-)$ & & & \\
\hline \multirow[t]{2}{*}{6} & 20 & M & 1 & Total & $\mathrm{C} 5$ & un- $R$ & 0 & 353,242 & 595 & $(-)$ & & & \\
\hline & & & & & C6 & $\mathrm{R}$ & 6.32 & $\begin{array}{l}2133,3188, \\
2028\end{array}$ & 7349 & SS & 6 & 30 & 48 \\
\hline 7 & 29 & M & 4 & Total & $\mathrm{C} 5$ & $\mathrm{R}$ & 8.62 & 3279,9890 & 13169 & SS & 5 & 30 & 20 \\
\hline 8 & 30 & M & 7 & Total & $\mathrm{C} 5$ & un-R & 0 & 1320 & 1320 & $(-)$ & & & \\
\hline 9 & 29 & M & 5 & $\mathrm{C} 5,6$ & $\mathrm{C} 5$ & un- $R$ & 0 & 166,461 & 627 & $(-)$ & & & \\
\hline 10 & 49 & M & 6 & $\mathrm{C} 5,6$ & $\mathrm{C} 5$ & un-R & 0 & 1129 & 1129 & $(-)$ & & & \\
\hline \multirow[t]{2}{*}{11} & 37 & M & 10 & Total & $\mathrm{C} 5$ & $\mathrm{R}$ & 13.7 & 8684 & 8684 & $\mathrm{SS}, \mathrm{PC}$ & 6 & 30 & 20 \\
\hline & & & & & C6 & $\mathrm{R}$ & 11.2 & 3602 & 3602 & LC & 18 & & \\
\hline \multirow[t]{2}{*}{12} & 27 & $\mathrm{~F}$ & 2 & Total & $\mathrm{C} 5$ & $\mathrm{R}$ & 0 & 2043 & 2043 & SS & 5 & 25 & 18 \\
\hline & & & & & C6 & $\mathrm{R}$ & 0 & 2409 & 2409 & SS & 5 & & \\
\hline 13 & 24 & M & 3 & $\mathrm{C} 5,6,7$ & $\mathrm{C} 5$ & un-R & 0 & 289 & 289 & $(-)$ & & & \\
\hline 14 & 69 & M & 1 & Total & $\mathrm{C} 5$ & un- $R$ & 0 & 955,545 & 1500 & $(-)$ & & & \\
\hline 15 & 32 & M & 2 & Total & $\mathrm{C} 5$ & un-R & 0 & 1056,233 & 1289 & $(-)$ & & & \\
\hline 16 & 18 & M & 5 & Total & $\mathrm{C} 5$ & $\mathrm{R}$ & 18.2 & 6916,5390 & 11400 & SS & 6 & 25 & 12 \\
\hline 17 & 5 & $\mathrm{~F}$ & 3 & Total & $\mathrm{C} 5$ & $\mathrm{R}$ & Not done & 7404 & 7404 & $\mathrm{SS}, \mathrm{PC}$ & 4 & 55 & 36 \\
\hline 18 & 6 & M & 5.5 & Total & $\mathrm{C} 5$ & un-R & Not done & 591,387 & 978 & $(-)$ & & & \\
\hline \multirow[t]{2}{*}{19} & 11 & M & 2 & Total & $\mathrm{C} 5$ & $\mathrm{R}$ & Not done & 2151 & 2151 & UT & 5 & 35 & 20 \\
\hline & & & & & C6 & $\mathrm{R}$ & Not done & 577,1506 & 2083 & UT & 5 & & \\
\hline
\end{tabular}

*R, repairable root; un- $\mathrm{R}$, un-repairable root

$\dagger$ LC, lateral cord; PC, posterior cord; SS, suprascapular nerve; UT, upper trunk

choline and acetyl-CoA labelled with ${ }^{14} \mathrm{C}$ was used to assess the activity. The root stump was resected and dissected into the fascicles under the operating microscope and a portion of each fascicle, $1.5 \mathrm{~mm}$ in length, was sent to the radioisotope laboratory. Because of dense scar tissue, separation into fascicles was sometimes impossible. The root was then evaluated as a single block of nerve tissue.

After separation of the specimen, the CAT activity was measured using a liquid scintillation counter (LSC-5100; Aloka Co Ltd, Tokyo, Japan). The preset time was one minute. Using this technique we found that the background, measured without the nerve sample, was approximately 100 counts per minute (cpm). The background was subsequently subtracted from each data point. The total amount of CAT activity of root was the sum of the values of each fascicle. This technique required 60 minutes from resection of the nerve slices to determination of the final results. Since the method required a cross-section specimen of the root, the study was confined to patients in whom the spinal root was disrupted, completely scarred or when there was a neuroma in continuity which registered none or few ESCPs.

Control study. Recently, we have used the contralateral seventh spinal root for neurotisation in brachial plexus injury and have investigated the normal value of CAT activity and ESCPs in the healthy spinal root in four of the residual stumps.
Decision making for intra-operative diagnosis. Traditionally, the site and severity of brachial plexus injury has been classified as either pre- or post-ganglionic. Since these lesions are usually due to traction, neural tissue may be damaged all along the course of the nerve giving a combination of pre- and post-ganglionic lesions. The purpose of operative exploration is to estimate the functional efficacy of the injured roots for a potential nerve graft, as well as to assess the extent of damage. Hence the simple classification as pre- and post-ganglionic injuries is not appropriate. We have classified the injured roots as repairable or unrepairable rather than as having pre- or post-ganglionic injury. ${ }^{10}$

Diagnosis was based on direct observation of the roots and on ESCPs recorded from each root. Based on their amplitudes, the recordings were classified into a nil or poor response (less than $5 \mathrm{uV}$ ) and a good response (more than $5 \mathrm{uV}$ ). A good response indicates that the injured root is repairable. ${ }^{4}$ Roots with no or a poor response were further assessed using the results of CAT activity. According to our criteria of selection of a donor nerve for a functioning free muscle transfer, fascicles with a CAT activity above $2000 \mathrm{cpm}$ are considered to have adequate quality and quantity. ${ }^{9,11}$ Thus, roots containing such fascicles were considered repairable, regardless of the level of the evoked spinal cord potentials. In four roots in three patients the diagnosis 
relied only on the CAT activity, since insertion of an epidural electrode for ESCPs was not technically possible.

All the results are presented as the mean \pm the standard deviation. The data were analysed by the Mann-Whitney U test and Spearman's rank correlation test. The 0.05 level of probability was established for statistical significance.

\section{Results}

From the control study, we determined that the mean amplitude of ESCPs in the healthy residual stumps of $\mathrm{C} 7$ was $96 \pm 19.6 \mathrm{uV}(\mathrm{n}=4)$ and the mean value of CAT activity was $9826 \pm 3548.6 \mathrm{cpm}(\mathrm{n}=3)$. Fifteen injured roots were assessed as un-repairable and ten were suitable for repair. The mean value of CAT activity in the un-repairable roots was $824 \pm 364.4 \mathrm{cpm}$ and in the repairable it was $6029 \pm$ $4029.3 \mathrm{cpm}$. The difference was statistically significant using the Mann-Whitney $\mathrm{U}$ test $(\mathrm{p}<0.01)$. The correlation between the amplitudes of the ESCPs and the value of CAT activity was statistically significant using Spearman's rank correlation test $(p<0.01)$. The levels of CAT activity and of the ESCPs were consistent in all except two roots (C5 and C6 in case 12).

The repairable roots were co-apted to the non-functioning target nerve via a sural nerve graft or a vascularised ulnar nerve graft. Since we routinely performed the doublefree muscle technique to reconstruct function of the elbow and fingers, ${ }^{12}$ the target nerves were always the suprascapular nerve or the upper trunk for reconstruction of shoulder stability. Evidence of the re-innervation of the supraspinatus and infraspinatus muscles was obtained using needle electromyograms within four to six months in all cases. The shoulder joints were stable with a mean active abduction of $33^{\circ}$ (25 to 55) at the final follow-up. The overall results are summarised in Table I.

\section{Discussion}

The CAT activity is considered to reflect the number of motor fibres (cholinergic fibres) in a cross-section of a nerve slice. ${ }^{8}$ Engel et $\mathrm{al}^{8}$ first described a rapid and precise method of identification of nerve fascicles based on the measurement of this activity. They also noted that the activity was higher in the motor compared to the sensory fascicles. This activity can assess the motor function of the nerve directly and quantitatively and each fascicle can be assessed individually. Quantitative assessment has been applied clinically in the intra-operative differentiation between motor and sensory fascicles during nerve grafting. ${ }^{13}$ We have found it useful in assessing the functional status of the donor nerve during the functioning free muscle transfer. ${ }^{9,11}$ The clinical application of CAT activity during surgery of the brachial plexus was first reported by Kawanishi, Yajima and Tamai. ${ }^{14}$ Based on a rat model of such injury, Yajima et $\mathrm{al}^{15}$ found that the activity in the avulsed roots decreased, reaching about $5 \%$ of the normal value five days after operation, while, in severed roots, the activity decreased only slightly and remained at $50 \%$ of the normal level, even after 90 days.

From our previous study ${ }^{7,9,11}$ we have concluded that the fascicles with activity greater than $2000 \mathrm{cpm}$ had an adequate quality and quantity of intact motor fascicles to function as the donor motor nerve for a functioning free muscle transfer. We have used the same levels on the current study and have found that the use of such roots could result in the re-innervation of the target muscles and useful motor recovery. However, the results of nerve grafting depend not only on the quality of donor root but also on many other factors, such as the interval between injury and surgery, the length of the nerve graft and the severity of the injury to the recipient non-functioning nerve.

We encountered two roots in which evoked spinal cord potentials were not recorded, although there was a level of CAT activity. We cannot explain this but suggest that it may have been due to a technical error in recording the potentials or possibly due to the injury being solely to the dorsal root. In five roots with a good level of ESCPs, the CAT level ranged from 3602 to $13169 \mathrm{cpm}$. The wide range of these values depends on the severity and extent of the injury, and the number of intact motor fibres in the ventral roots, and indicates the usefulness of this measurement activity in the quantitative assessment of motor function in the ventral roots, thus predicting the results of nerve grafts. Although ESCP can be quantitatively assessed by its amplitude, it mainly records the nerve potentials along the afferent sensory pathway. Moreover, the largest amplitude in this series was $18.2 \mathrm{uV}$ which was only about $20 \%$ of that found in the control root.

Shoulder stabilisation or elevation is important in providing a greater range of movement for the reconstructed hand in patients with total plexus injuries. ${ }^{12}$ However, no method of reconstruction can achieve more than $90^{\circ}$ of abduction of the shoulder. ${ }^{16}$ Chuang et al, ${ }^{16}$ noted that the simultaneous neurotisation of the suprascapular and axillary nerves with the phrenic and spinal accessory nerves was the most reliable option. This technique obtained a mean of $55^{\circ}$ of abduction. Using repair of the roots, we obtained shoulder stability with a mean abduction of $33^{\circ}$.

Our intra-operative assessment of injuries to the brachial plexus is based on the use of ESCPs and measurement of CAT. The former can be quickly assessed but difficulties may be encountered in introducing the electrode into the spinal canal due to scar formation. It cannot be carried out in children. Measurement of the level of CAT requires a specimen from the nerve and the resources of a radioisotope laboratory, but it does give accurate assessment of the level of potential motor function.

The major role of ESCPs is the screening to confirm the central continuity. If the amplitude of ESCPs is more than $5 \mathrm{uV}$, the root can be considered repairable. Measurement of CAT activity can predict the result of nerve graft with its quantitative assessment. If it is less than $5 \mathrm{uV}$, further 
diagnosis using CAT activity should be necessary to prevent the false-negative result of ESCPs. These two techniques should be complementary to each other, so that more accurate and useful reconstruction can be performed.

No benefits in any form have been received or will be received from a commercial party related directly or indirectly to the subject of this article.

\section{References}

1. Landi A, Copeland SA, Parry CBW, Jones SJ. The role of somatosensory evoked potential and nerve conduction studies in the surgical management of brachial plexus injuries. J Bone Joint Surg [Br] 1980;62-B: 492-6.

2. Sugioka H, Tsuyama N, Hara T, et al. Investigation of brachial plexus injuries by intra-operative cortical somatosensory evoked potentials. Arch Orthop Trauma Surg 1982;99:143-51.

3. Murase T, Kawai H, Masatomi T, Kawabata H, Ono K. Evoked spinal cord potentials for diagnosis during brachial plexus surgery. J Bone Joint Surg [Br] 1993;75-B:775-81.

4. Sasaki Y, Fuchigami Y, Kawai S, Kaneko K, Doi K. Intraoperative electrodiagnosis for brachial plexus injury. In: Teoh L-C, Lim B-H, eds. Hand surgery in the next millenniun. Bologna: Monduzzi Editore, 1999:223-6

5. Turkof E, Millesi H, Turkof R, Pfunder P, Mayr N. Intraoperative electroneurodiagnostics (transcranial electrical motor evoked potentials) to evaluate the functional status of anterior spinal roots and spinal nerves during brachial plexus surgery. Plast Reconstr Surg 1997;99: 1632-41.

6. Sunderland S. Mechanism of nerve root avulsion in injuries of the neck and shoulder. J Neurosurg 1974;41:705-14.
7. Hattori Y, Doi K, Fukushima S, Kaneko K. The diagnostic value of intraoperative measurement of choline acetyltransferase activity during brachial plexus surgery. $J$ Hand Surg $[B r]$ 2000;25:509-11.

8. Engel J, Ganel A, Melamed R, Rimon S, Farine I. Choline acetyltransferase for differentiation between human motor and sensory nerve fibres. Ann Plast Surg 1980;4:376-80.

9. Hattori Y, Doi K, Kaneko K, Heong TS. Intraoperative measurement of choline acetyltransferase activity to evaluate the functional status of donor nerve during reinnervated free muscle transfer: a preliminary report. J Hand Surg [Am] 1998;23:1034-7.

10. Hentz VR. Microneural reconstruction of the brachial plexus. In: Green DP, ed. Operative hand surgery. Vol. 2. Third ed. New York: Churchill Livingstone, 1982:1223-52.

11. Hattori Y, Doi K, Ohi R, et al. Clinical application of intraoperative measurement of choline acetyltransferase activity during functioning free muscle transfer. J Hand Surg [Am] 2001;26-A:645-8.

12. Doi K, Muramats K, Hattori Y, et al. Restoration of prehension with the double free muscle technique following complete avulsion of brachial plexus. J Bone Joint Surg [Am] 2000;82-A:652-66.

13. Ganel A, Farine I, Aharonson Z, et al. Intraoperative nerve fascicle identification using choline acetyltransferase. Clin Orthop 1982; 165:228-32.

14. Kawanishi K, Yajima H, Tamai S. Choline acetyltransferase activity: application for the diagnosis and treatment of brachial plexus injury. Second Report. J Jpn Soc Surg Hand 1992;9:464-8.

15. Yajima H, Kawanishi K, Ohgushi H, Tamai S. Experimental study on choline acetyltransferase activity for brachial plexus injury. Microsurgery 1995;16:679-83.

16. Chuang DCC, Lee GW, Hashem F, Wei F. Restoration of shoulder abduction by nerve transfer in avulsed brachial plexus injury: evaluation of 99 patients with various nerve transfers. Plast Reconstruct Surg 1995;96:122-8. 